\title{
Gestão de memórias e narrativas identitárias: conflitos e alianças em contextos interétnicos
}

\author{
Marta de Oliveira Antunes ${ }^{1}$ \\ Instituto Brasileiro de Geografia e Estatística
}

Katiane Silva2

Universidade Federal do Pará

\begin{abstract}
Resumo: Neste texto, as autoras propõem-se a colocar em diálogo dois processos de territorialização (Oliveira, 2002; 2004) que se entrelaçam com a busca de efetivação de direitos focalizados para "novas" e "velhas" etnias, que ocorreram e ocorrem em dois contextos etnográficos distantes geograficamente, ambos atravessados por situações históricas (Oliveira, 1986;1999), que moldam e criam condições de possibilidades para que autoidentificações étnicas discordantes entre membros das mesmas "famílias" sejam acionadas. Nesses contextos a "gestão territorial" está em processo, em Auati-Paraná esta assume a forma de uma "tutela ambientalista" (Silva, 2015), administrada pelo "Estado"; e, no caso de Conceição das Crioulas, está em construção uma proposta de uma "gestão territorial comunitária" (Antunes, 2016), administrada pela associação local. Os conflitos perpassam essas gestões territoriais e informam a gestão de memórias e de narrativas identitárias, que permitem desenhar fronteiras étnicas entre parentes que sistematizam de forma diferenciada fluxos culturais que os atravessam.
\end{abstract}

Palavras-chave: Cocama, Quilombolas, Conflitos, Território. 


\title{
Gestión de memorias y narrativas identitarias: conflictos y alianzas en contextos interétnicos
}

Resumen: En este texto, las autoras se proponen poner en diálogo dos procesos de territorialización (Oliveira, 2002; 2004) que se entrelazan con la búsqueda de efectivación de derechos focalizados para "nuevas" y "viejas" etnias, que ocurrieron y ocurren en dos los contextos etnográficos distantes geográficamente, ambos atravesados por situaciones históricas (Oliveira, 1986; 1999), que moldean y crean condiciones de posibilidades para que las autoidentificaciones étnicas discordantes entre miembros de las mismas "familias" sean accionadas. En estos contextos la "gestión territorial" está en proceso, en Auati-Paraná ésta asume la forma de una "tutela ambientalista" (Silva, 2015), administrada por el "Estado"; y, en el caso de Concepción de las Criollas, está en construcción una propuesta de una "gestión territorial comunitaria" (Antunes, 2016), administrada por la asociación local. Los conflictos atravesan estas gestiones territoriales e informan la gestión de memorias y narrativas identitarias que permiten dibujar fronteras étnicas entre parientes que sistematizan de forma diferenciada los flujos culturales que los atravesan.

Palabras clave: Cocama, Quilombolas, Conflictos, Territorio.

\section{Management of memories and identity narratives: conflicts and alliances in interethnic contexts}

\begin{abstract}
In this paper, the authors propose to put into dialogue two processes of territorialization (Oliveira, 2002; 2004) that intertwine with the search for effective rights focused on "new" and "old" ethnicities that occurred and occur in two geographically distant ethnographic contexts, both crossed by historical situations (Oliveira, 1986, 1999), which shape and create conditions of possibilities for discordant ethnic self-identification between members of the same "families" to be triggered. In these contexts "territorial management" is in process, in Auati-Paraná this takes the form of an "environmental tutelage" (Silva, 2015), administered by the "State"; and in the case of Conceição das Crioulas, a proposal for a "community territorial management" (Antunes, 2016) run by the local association is under construction. Conflicts permeate these territorial management and inform the management of memories and identity narratives, which allow the drawing of ethnic boundaries between relatives that differentiate the cultural flows that cross them.
\end{abstract}

Keywords: Cocama, Quilombolas, Conflicts, Territory. 


\section{Introdução}

Neste texto, as autoras propõem-se a colocar em diálogo dois processos de territorialização (Oliveira, 2002; 2004) que se entrelaçam com a busca de efetivação de direitos focalizados para "novas" e "velhas" etnias, que ocorreram e ocorrem em dois contextos etnográficos distantes geograficamente, ambos atravessados por situações históricas (Oliveira, 1986; 1999) que moldam e criam condições de possibilidades para que autoidentificações étnicas discordantes entre membros das mesmas "famílias" sejam acionadas, com implicações nas redes de alianças tecidas localmente.

Como apontado por Almeida, a retomada das mobilizações camponesas pós-1988, tem no fator étnico um componente político-organizativo (Almeida, 2008: 58), que provoca uma reflexão sobre o que denomina de "novas etnias", não como oposição a "velhas etnias", mas como deslocamentos no conceito de etnia:

\footnotetext{
Se de um lado se reconhece que há etnias permanentes, cujas origens são centenárias, de outro se reconhece também o advento de 'novas etnias' conceituadas como uma tendência de grupos se investirem, num sentido profundo, de uma identidade cultural com o objetivo de articular interesses e reivindicar medidas, fazendo valer seus direitos, face aos aparatos de estado. O critério político-organizativo ajuda a relativizar o peso de uma identidade definida pela comunidade de língua, pelo território, pelo fator racial ou por uma origem comum (Almeida, 2008: 82).
}

Nos dois contextos etnográficos os grupos acionam as categorias "indígena”, "quilombola”, "extrativista” ou "ribeirinho" como categorias étnicoidentitárias em sua mobilização sociopolítica e no âmbito de seu relacionamento com o "Estado" na reivindicação de direitos e ação estatal.

Nos dois contextos etnográficos a "gestão territorial” está em processo, em Auati-Paraná esta assume a forma de uma "tutela ambientalista" (Silva, 2014; 2015) administrada pelos órgãos vinculados ao "Estado", e no caso de Conceição das Crioulas está em construção uma proposta de uma "gestão territorial comunitária" (Antunes, 2016) em que a administração está a cargo da associação local. Nesse sentido, os conflitos perpassam essas gestões territoriais e informam a gestão de memórias e de narrativas identitárias, que permitem desenhar fronteiras étnicas, num sentido barthiano, entre parentes que sistematizam de forma diferenciada fluxos culturais3 que os atravessam.

O primeiro contexto etnográfico trata do conflito na região do AuatiParaná, no estado do Amazonas, no qual os membros da família Arantes dividem-se entre indígenas Cocama, da comunidade Santa União, e seus parentes que não se consideram indígenas, da comunidade Itaboca. Ambas estão localizadas dentro dos limites da Reserva de Desenvolvimento Sustentável 
(RDS) Mamirauá e da Reserva Extrativista (Resex) Auati-Paraná4 e esta configuração implica num arranjo institucional no qual as diversas instituições envolvidas na mediação dos conflitos, como a Igreja e o Estado, estão completamente imbrincadas. Além disso, os setores político, econômico, religioso e as relações de parentesco são co-produtoras da construção histórica de Fonte Boa, município sede dessas comunidades.

Os Arantes são descendentes de indígenas Cocama que se deslocaram de diversas localidades do Peru no final do século XIX e início do século XX. De acordo com o senhor Ventura Arantes5, "o pessoal no Peru já vivia assustado. Quando via barco assim, já corria pro mato pra se esconder. Daí eles vinham embora pro Brasil porque aqui eles ia ter uma vida boa, uma vida livre”. O deslocamento compulsório de indígenas e não indígenas peruanos para o trabalho nos seringais dos rios Purus, Madeira, Juruá era significativo, posto que constantemente é enfatizado nos relatos dos participantes da pesquisa em Fonte Boa. Deste modo, Ventura destacou: "Aqui a senhora pode ver que a maioria é gente do Peru", sendo importante frisar também a presença da migração nordestina. A formação de localidades, a partir da migração peruana, não estava restrita apenas às comunidades Itaboca e Santa União, mas ao conjunto de comunidades que compõem parte da Resex Auati-Paraná e RDS Mamirauá.

A rota comercial entre Brasil e Peru, no início do século XX, era intensa e transitavam mercadorias, produtos agrícolas e pessoas. Ao desembarcar no Auati-Paraná, os Arantes encontraram diversos parentes e conhecidos ao longo do Rio, trabalhando como fregueses dos grandes comerciantes locais, cujos negócios se estendiam por uma grande rede comercial de Nauta à Manaus.

Petesch (2003), observou que o deslocamento dos Cocama ao longo da história e expansão da economia gomífera, correu desde Nauta, no Peru, até Manaus. A partir da análise de documentos oficiais e em relatos de um dos últimos falantes da língua Cocama de La Playa, uma reserva indígena peruana, Petesch chama atenção para a produção de narrativas que enfatizam a relação íntima entre a nacionalidade e a etnia: só os Cocama nascidos no Peru e falam a língua indígena é que são considerados "verdadeiros" ou "puros". É interessante notar que a origem peruana também é acionada pelos Cocama de Santa União. Eles se consideram Cocama "verdadeiros" ou "puro sangue" justamente porque são descendentes de peruanos. Deste modo, a origem peruana comum é um elemento fundamental para a legitimidade da identidade Cocama.

4A RDS Mamirauá foi criada, inicialmente, como categoria Estação Ecológica, em 1996, por meio do decreto $\mathrm{n}^{\circ} 12.836$ de 9 de março de 1990. Possui 1.124.00o hectares, está localizada nos municípios de Uarini, Fonte Boa e Maraã, sendo também influenciada pelos municípios de Jutaí, Alvarães e Tefé. A mudança de categoria ocorreu graças às pressões feitas pela população que vivia na região, pois a modalidade Estação Ecológica (EE) não permite a presença de pessoas em seu território. Nesse sentido, a categoria Reserva de Desenvolvimento Sustentável foi criada e implementada graças aos desdobramentos ocorridos a partir da criação da EE Mamirauá em 16 de julho de 1996 (Silva, 2015). A Resex AuatiParaná é uma unidade de conservação federal de uso sustentável, criada a partir do Decreto de 7 de Agosto de 2001. Está localizada no Município de Fonte Boa/AM e possui aproximadamente uma área de 147.597.0o ha ao longo do rio AuatiParaná. As dezesseis comunidades que compõem a Resex Auati-Paraná estão distribuídas tanto à margem direita (dentro dos limites da RDS Mamirauá) quanto esquerda (dentro dos limites da Resex) do Rio Auati-Paraná.

5 Filho de João Dario Arantes, um dos primeiros peruanos da etnia Cocama a chegar no Auati-Paraná, conforme mencionado anteriormente. João Dario Arantes era um exímio pescador de pirarucu e estabeleceu moradia na Foz do Mamoriá, onde trabalhou como freguês do temido patrão seringalista Benjamin Affonso. 
Silva $(2014 ; 2015)$ defende que o modo como os conflitos se desenrolaram e como os indígenas foram e são tratados e retratados atualmente é decorrente da relação de patronagem e do violento sistema dos barracões instalado durante o período de intensa exploração da seringueira no final do século XIX e início do século XX. Para compreender este contexto é preciso lembrar que o modo como as elites, na figura do "patrão da borracha" ou do "coronel de barranco", redesenharam o cenário territorial e político do Alto Solimões foi marcado pela violência e a exploração tanto dos recursos naturais quanto da força de trabalho de indígenas e não indígenas.

A partir da noção de território enquanto um dos elementos essenciais na administração do Estado (Weber, 1983), a autora percebeu em campo que diversas instituições "pacificadoras" (leia-se organizações estatais e não governamentais) domesticaram os conflitos sociais e pessoais à medida que colocaram em prática um projeto de controle e uso racional dos recursos naturais. Isso se traduziu ainda na criação de estratégias de classificação dos índios, tanto em documentos oficiais quanto no cotidiano, num cenário onde a imposição de uma harmonia fantasiosa incitava conflitos com pressupostos utilitaristas no controle e desenvolvimento regional: a Amazônia e tudo o que nela está contido é naturalizado e essencializado como um imenso "bem” a ser reservado ou preservado.

O segundo contexto etnográfico tem como locus o território quilombola de Conceição das Crioulas, território que compartilha seu nome com o II Distrito do município de Salgueiro, onde se localiza, se aproximando e cruzando as divisões municipais dos municípios de Mirandiba, Carnaubeira da Penha e Belém de São Francisco, no estado de Pernambuco.

A história de origem comum (Weber, 2002) de Conceição das Crioulas vem sendo transmitida de geração em geração pela oralidade, recorrendo a histórias de trancoso6 e de um personagem local - Barnabé de Oliveira7 -, e pode ser sintetizada, eliminando as variações inerentes ao recontar na oralidade, no seguinte texto:

\footnotetext{
Contam as pessoas mais velhas que em meados do século XVIII, seis negras chegaram à região e arrendaram uma área de três léguas em quadras. Começaram a plantar algodão e com a produção e fiação que vendiam na cidade de Flores, situada também no sertão pernambucano, conseguiram pagar a referida renda e ganharam o direito de adquirir o título de suas terras. Não há um consenso quanto ao local de origem dessas mulheres, nem das razões que as levaram a se deslocar para esta região. Conta ainda a história oral da comunidade que, em 1802, as crioulas receberam a escritura com o carimbo da Torre, dezesseis selos, feita por José Delgado, escrivão do cartório de Flores, fazendo referência à época do império. Um homem chamado Francisco José, fugido de uma guerra, trouxe consigo a imagem de Nossa Senhora da Conceição. Ao chegar nas terras das crioulas tiveram a ideia de construir uma capela e tornar a santa sua padroeira. Surgiu assim o nome da comunidade: Conceição das Crioulas. (AQCC, 2013: 10-11)
}

6 Histórias de trancoso ou histórias de mau-assombro são histórias que assustam pela presença de animais predadores, como onça ou raposa, ou de espíritos.

7 Barnabé de Oliveira é um ancestral dos crioulos e crioulas de Conceição e suas histórias são repletas de "exagero", como afirmam seus descendentes, e provocam o riso, elemento que se torna essencial na memorização das mesmas e, consequentemente, das informações nelas contidas. 
Reconhecida como "comunidade remanescente de quilombo" em 2000, pela Fundação Cultural Palmares (FCP), e titulada no mesmo ano8, a comunidade quilombola mantém-se mobilizada e atuante na busca da finalização do processo de regularização fundiária do seu território até ao momento atual. Esse processo de regularização passa a partir de 2003, com a emissão do Decreto $\mathrm{n}^{0}$ 4.8879, para a responsabilidade do Instituto de Colonização e Reforma Agrária (INCRA) e em 2012 a primeira fazenda, das mais de vinte que estão inseridas no perímetro, é desintrusada1o, ou seja, seu "dono" é indenizado pela União e a titularidade desse terreno passa a ser da Associação Quilombola de Conceição das Crioulas (AQCC), enquanto representante da comunidade quilombola - forma encontrada para concretizar de forma administrativa e burocrática um direito coletivo à propriedade da terra, num país cujo corpo legislativo e normativo prima pela defesa da propriedade privada11.

Recorrendo à ideia de "situação histórica" (Oliveira, 1986: 58-59; 1999a: 9) efetuamos recortes analíticos na história dos dois grupos étnicos (Barth, 2000; 2003) com os quais desenvolvemos nossas pesquisas, tendo como marcadores de corte entre as diferentes situações históricas as mudanças nas relações de dominação que atravessavam e organizavam as relações sociais nesses grupos. Selecionamos assim, três situações históricas - Barracão e fatiamento; Comunização etnicopolítica; e Gestão territorial - a partir das quais pretendemos estabelecer pontos de confluência entre esses dois contextos etnográficos e pensar a gestão de memórias e narrativas identitárias, assim como a gestão de alianças e conflitos, alinhadas com a ideia de que uma "situação histórica":

[...] não se refere a eventos isolados, mas a modelos ou esquemas de distribuição de poder entre diversos atores sociais. [...] O que assim se designa é o resultado de uma análise situacional, pressupondo portanto o manuseio de situações sociais [...] e da noção de campo. Trata-se de uma construção do pesquisador, uma abstração com finalidades analíticas, composta dos padrões de interdependência entre os atores sociais, e das fontes e canais institucionais de conflito, permitindo captar os fundamentos e a efetividade da capacidade organizadora de todos esses elementos face aos processos sociais concretos verificados em uma situação. (Oliveira, 1986: 5859 - grifos no original)

8A área titulada do território pela FCP, de acordo com o memorial descritivo, é de 16.865,0678 hectares.

9 O Decreto $n^{0}$ 4.887/2003 substituiu o Decreto $n^{0}$ 3.912/2001, sendo ambos instrumentos de concretização do artigo 68 do Ato de Disposições Constitucionais Transitórias (ADCT) da Constituição Federal de 1988 que prevê a titulação de territórios de comunidades quilombolas. Enquanto o decreto de 2001 não se preocupou com a conceituação que embasava a seleção de quem é o "público alvo" do artigo 68 do ADCT, remetendo para o "Relatório Técnico" a "identificação dos aspectos étnicos, histórico, cultural e socioeconômico do grupo" (inciso $1^{\circ}$ do artigo $3^{\circ}$ do Decreto no 3.912/2001), o decreto de 2003 avança um conceito de "remanescentes das comunidades dos quilombos" tendo por base a "autodefinição" (inciso $1^{\circ}$ do artigo $2^{\circ}$ do Decreto $n^{\circ} 4.887 / 2003$ ) e altera o conceito de "terras ocupadas" ao retirar os marcos cronológicos de 1888 e 1988 e inserindo a ideia de ocupação como utilização que garante a reprodução física, social, econômica e cultural do grupo étnico-racial (inciso $2^{\circ}$ do artigo $2^{\circ}$ do Decreto $n^{\circ} 4.887 / 2003$ ).

10 Surge com o Decreto ${ }^{\circ} 4.887 / 2003$ a figura de desapropriação de domínios particulares com títulos não invalidados (artigo $13^{\circ}$ ), a figura do reassentamento de famílias de agricultores ocupantes nas terras dos remanescentes das comunidades dos quilombos quando estas pertencerem à clientela da reforma agrária (artigo $14^{\circ}$ ) e a figura da indenização das benfeitorias de boa-fé (artigo $14^{\circ}$ ). Esses artigos abrem a possibilidade de adicionar uma nova etapa ao processo que passa a se denominar com o decreto 4.887/2003 de regularização fundiária, que é a etapa de desapropriação, reassentamento e indenização de benfeitorias. Essa etapa começa a ser denominada de "desintrusão", na Instrução Normativa ${ }^{\circ} 20$ do INCRA que: "Regulamenta o procedimento para identificação, reconhecimento, delimitação, demarcação, desintrusão, titulação e registro das terras ocupadas por remanescentes das comunidades dos quilombos de que tratam o Art. 68 do Ato das Disposições Constitucionais Transitórias da Constituição Federal de 1988 e o Decreto $\mathrm{n}^{\circ} 4.887$, de 20 de novembro de 2003 " (IN n $\left.{ }^{\circ} 20,2005\right)$.

11 Para uma discussão a respeito ver Shiraishi (2007: 28-29). 


\section{Barracão e fatiamento}

O primeiro recorte efetuado teve como marcadores de corte as relações entre os que hoje se autoidentificam indígenas em Auati-Paraná e quilombolas em Conceição das Crioulas com a figura dos "patrões". A relação entre membros dos dois grupos étnicos e seus patrões foram e são perpassadas por processos de mudança na relação do grupo com sua identidade e seu território, criando possibilidades de alianças diferenciadas nos períodos recortados e influenciando essas possibilidades em momentos futuros, ao se enraizarem e comporem a memória oral dessas populações.

Essa primeira situação foi recortada, pois ela permite invisibilizar o sentimento de pertença a um grupo de parentesco que se distingue do entorno e por reforçar vínculos individualizados entre patriarcas ou matriarcas e os patrões como forma de manutenção das estratégias de reprodução que se tornam cada vez mais familiares e menos grupais.

\section{Auati-Paraná, invisibilização étnica, branqueamento e regime de barracão}

Os municípios de Fonte Boa e Jutaí, localizados no Rio Solimões possuem uma história comum: ambos fazem parte de uma região caracterizada por grandes disputas político-administrativas e de exploração tanto dos recursos naturais (borracha, castanha, pirarucu, ovos de tartaruga, entre outros), como da força de trabalho de indígenas e de migrantes nordestinos. Enquanto a vocação do Rio Jutaí era a exploração massiva da borracha, no Auati-Paraná a principal produção era, e ainda é, a pesqueira, com destaque para a pesca de pirarucu.

A atividade econômica se concentrava, no início do século $\mathrm{XX}$, ao longo dos rios, que representavam a comunicação na região e com o resto do mundo. Os grandes portos de exportação e abastecimento de pirarucu seco estavam localizados em Tefé, Caiçara (atual Alvarães) e Coari, municípios que centralizavam praticamente toda a pesca do "delta do Japurá", e cujos comerciantes enviavam mais de cem toneladas de peixe a Manaus e Belém. O Rio Solimões era constantemente visitado por barcos a vapor que vinham apanhar os principais produtos de exportação da época: borracha, castanha, pirarucu seco e palmito (Tastevin, 2008). 
Os seringais estavam localizados em áreas distantes, no Auati-Paraná e Fonte Boa a dentro (considerando o que hoje é o município de Jutaí), nas regiões de terra-firme, obrigando os seringueiros, nos primórdios dessa exploração, a passarem os meses da seca isolados na floresta trabalhando na coleta do látex. No final do século XIX, Fonte Boa é retratada como um vilarejo simples, com locais pantanosos e povoado formado por índios e "mestiços receptivos" (Bates, 1979; Bastos, 1975).

A situação fundiária começa a se modificar a partir da busca por seringais, em 1870, sendo explorado primeiramente o caucho e, em seguida, a borracha. Em geral, as localidades com ocorrência de hevea brasiliensis eram habitadas por indígenas, que resistiam ao domínio dos exploradores externos (Reis, 1953; Teixeira, 2009). Conforme as terras eram "conquistadas" à força, eram executados os trabalhos de demarcação e requerimento do título de propriedade, baseado na Lei $\mathrm{n}^{0} 1.114$, de 27 de setembro de 1860.

A exploração da borracha vinha ocorrendo desde a primeira metade do século XIX. Conforme a procura pelo produto foi crescendo, a pressão sobre a mão-de-obra indígena também aumentou. Essa exploração somente diminuiu a partir dos anos de 1880, quando foi gradualmente substituída pelos nordestinos (Teixeira, 2009). Isto não significou o desaparecimento total da exploração da mão-de-obra indígena.

O controle social e territorial, por meio do Estado, se estendia desde os seringais e propriedades dos grandes comerciantes e elites locais, até as capitais Manaus e Belém. A necessidade de estruturação dessas cidades era considerada emergencial para se adaptarem a este sistema econômico, político e cultural: o aterramento de igarapés, utilizados no cotidiano da população, bem como a tentativa de apagamento dos costumes considerados indígenas para a imposição de uma nova subjetividade urbana, imposta pela administração municipal (Dias, 2007).

Já no interior do estado do Amazonas o controle territorial e dos corpos, por meio da violência, era cada vez mais intensificado. A configuração política de Fonte Boa era permeada por constantes disputas pelos cargos administrativos, já que governar este município significava controlar um importante entreposto comercial e uma verdadeira reserva de recursos naturais (fauna e flora) a serem explorados. Nessas disputas político-econômicas havia também a presença marcante dos representantes da Igreja em cargos importantes da administração locais, como, por exemplo, os cargos de professores, ou responsabilidades em cartórios e até nas intendências municipais.

O comércio e a relação de patronagem local constituíam-se a partir da disseminação do sistema de aviamento, ou seja, o adiantamento de mercadorias e instrumentos de trabalho a crédito pelo patrão ao freguês, que tinha obrigação de restituir a dívida com sua produção. Este sistema se desenvolveu na Amazônia desde o período colonial e se expandiu durante o auge da exploração da borracha, marcada pelo terror, maus-tratos e exploração dos corpos e da força de trabalho de indígenas e não indígenas. Esta relação de dominação é 
central no funcionamento da rede comercial da Amazônia, cuja principal característica é a privação do trânsito local, da liberdade de ir e vir.

Para-além da reclusão aos interiores da floresta com o objetivo de se proteger da expansão do "homem branco", "civilizado" ou "colonizador", os indígenas passaram por um processo de violência e repressão. No entanto, mantiveram suas histórias e ressignificaram o que entendem por cultura, nos dias atuais, com a luta e mobilização para a criação das terras indígenas, como o caso dos indígenas Cocama de Santa União.

\section{Fatiamento e reminiscências do cativeiro}

Em Conceição das Crioulas, a memória do grupo remete para um período em que a comunidade se organizava em "territórios familiares"12 dentro de um grande território pensado como herança das seis crioulas fundadoras13 que na memória coletiva do grupo eram livres do sistema escravista, seja por serem fugitivas de alguma fazenda, seja por terem nascido livres em outro quilombo, talvez Palmares. Esse período atravessa os séculos XVIII e XIX, sendo essa organização do território e das relações socioculturais, políticas e econômicas que o modificavam e que por ele eram influenciadas ameaçada no início do século XX, momento em que um cartório e duas cadeias são instalados na sede do II Distrito do município de Salgueiro, local hoje denominado de Vila Centro de Conceição das Crioulas, e que o exército é acionado para "manter a ordem” e "pacificar"14 qualquer tentativa de resistência ao processo de expropriação fundiária, num momento em que o combate ao banditismo e ao cangaço justificavam ações enérgicas do "Estado".

Com a chegada do "Estado" pacificador pessoas são individualizadas e registradas, adentrando a burocracia estatal e tornando-se passíveis de serem cidadãs, assim como de serem classificadas como "desordeiras" ou "criminosas". Concomitantemente o território em comum começa a ser desmembrando através de uma série de registros territoriais nos cartórios, que se iniciam em 1920, concentram-se no período entre 1936 e 1949, estendendo-se até ao final da década de 1970, transformando "terras em comum" em "terras próprias" ou "terras de dono".

Contam os "mais velhos" que os registros das terras ocorriam à força e que os que resistiam eram presos: "[...] no tempo dos coronéis a gente perdeu, que a gente não tinha força, não tinha poder [...]". Contam também que muitos dos que registraram terras dentro do território, foram acolhidos pelos crioulos e crioulas de Conceição, num gesto de solidariedade, quando os primeiros pediam espaço para fazer um logradouro e colocar um gado. Esses aos poucos iam

12 A ideia de "territórios familiares" foi acionada por uma liderança quilombola de Conceição das Crioulas para se referir à organização da gestão territorial pré-fatiamento, que deixava para os patriarcas e matriarcas das famílias a tomada de decisão sobre a utilização de porções do território sem a implicação numa divisão material do mesmo, estratégias de gestão que se mantêm até hoje (Ântunes, 2016).

13 A memória do grupo remete para uma escritura que data de 1802 e que se refere a terras em comum.

14 Para uma discussão sobre o termo pacificar, ver Oliveira (2004). 
ampliando o espaço cedido, cercando o mesmo e, quando se davam conta, os crioulos e crioulas haviam perdido o direito sobre seus territórios familiares e a comunidade sobre seu território coletivo.

O "fatiamento do território" (Antunes, 2016) e a expropriação das famílias de seus territórios familiares provocou uma alteração nas relações socioeconômicas, com o surgimento da figura do "dono da terra" ou do "patrão", comumente denominado de "coronel", que transforma crioulas e crioulos em empregados, num sistema que apresenta paralelos com a volta do "cativeiro". Com dois terços do território tomado por "fazendas", ficando fora das cercas as terras menos produtivas - com pedras, longe dos cursos de água e nas encostas das serras e dos serrotes - a população vai sendo aos poucos enredada num sistema de relações de patrono-cliente com esses que os expropriaram, para garantir sua sobrevivência e reprodução: “[...]continuamos trabalhando no mesmo terreno pagando renda, que ele tirou a terra, mas não tirou a gente de cima [...]". Como coloca uma historiadora da comunidade "[...] é tudo cercado, a gente vive cercado, que quase que antigamente como se fosse cativeiro, não tem direito a mais nada, a não ser só aquele quadrinho ali, onde era três léguas em quadro, só vê aquilo ali...” (Maria Emília da Silva, Laudo Antropológico, Souza, 1998: 24-25).

A gestão do território deixa de ser pautada pelas relações de parentesco e de ajuda mútua entre parentes, são os laços individualizados entre o "pai de família" ou a "mãe de família" e o "patrão" que permitem que os membros das famílias continuem utilizando seus "territórios familiares" mediante um acordo de meia ou terça, contraindo dívidas morais e econômicas com esses "patrões". Apenas o artesanato local escapava parcialmente dessa relação com os "donos da terra”, quando a matéria-prima podia ser encontrada fora das cercas, ou quando os artesãos e artesãs "roubavam" a mesma de dentro das cercas sem serem vistos. Outras estratégias de reprodução empreendidas pelos descendentes das crioulas passavam pela migração para as cidades de Salgueiro, Recife ou do Sudeste, para as mulheres havia a possibilidade de trabalhar nas "casas de família"15, principalmente em Salgueiro, para os homens a mobilidade no entorno de Conceição das Crioulas, estabelecendo relações de "trabalho" com outros fazendeiros. Contudo, ao deixarem suas casas em Conceição das Crioulas, as relações estabelecidas com esses fazendeiros e com as patroas operavam numa lógica que envolvia a contração de dívidas pela moradia e/ou pela feira, a obrigatoriedade de estar disponível para trabalhar sempre que solicitado/a (que acontecia também com aqueles que apenas tinham acesso a terras numa relação de meia/terça, mesmo morando em Conceição das Crioulas), deixando muitos dos que saíram em sistemas de trabalho de semi-escravidão.

O "fatiamento do território" provoca não só uma profunda reorganização na forma de acesso à terra enquanto recurso produtivo, mas também no acesso 
a outros recursos naturais, como água, produtos que eram extraídos da caatinga e espaços de memórias que eram e são essenciais para a manutenção do modo de ser e viver do grupo de descendentes das seis crioulas fundadoras.

O processo de desterritorialização desse grupo provocou alterações radicais na forma como o grupo passou a se pensar, em particular na rede de alianças que passam a ser tecidas entre os do grupo e os de fora do grupo, num movimento que esgarça as relações de parentesco que uniam a população de Conceição das Crioulas numa "grande família", com papel chave para as relações dentro dos principais troncos familiares. Passam a valorizar o estreitar relações com os "patrões", aqueles que são de fora, mas que se intrusam dentro do território e aos poucos dentro das relações sociais e familiares ao apadrinhar os filhos e filhas dos descendentes das crioulas e ao estabelecer matrimônio com os "de dentro".

A relação com os coronéis passa a ser um meio para acessar infraestrutura de estocagem de água na seca, o carro-pipa distribuído nas emergências, as frentes de trabalho, as diárias, para acessar o hospital, ser atendido por um médico, comprar um remédio, acessar um carro para levar uma mulher grávida que enfrentou complicações no parto para a cidade, levar um doente, trazer e enterrar um defunto, dirimir uma contenda... envolvendo os descendentes das crioulas em relações de dom-dádiva (Mauss, 2003) com os patrões.

Mas não é sem resistência, como lembram as lideranças quilombolas, que esse processo de expropriação ocorre e algumas lideranças assumem um papel chave na manutenção da história do grupo e na busca de reterritorializar o mesmo, impedindo que o terço do território que não foi tomado pela grilagem se perca. Entre essas lideranças que se transformaram em personagens da memória Antunes (2016) destaca Agostinha Cabocla, que se agarra à história e à escritura original de 1802 para defender o território coletivo, reiterando que nenhuma parte do mesmo poderia ser vendida sem a assinatura de todos os descendentes de Conceição das Crioulas, viajando “de pés” para várias cidades buscando a garantia da reversão do "fatiamento" do território em comum. Seu papel é de reagregação do grupo, buscando estreitar os laços entre parentes e expulsar os intrusos e é por conta da história que ela manteve viva, assim como outras historiadoras e historiadores da comunidade, que anos mais tarde foi possível recuperar um sentimento de pertença a um grupo unido por laços de parentesco, uma história de origem comum e uma história de luta comum, como apresentaremos na próxima situação histórica.

\section{Comunização etnicopolítica: narrativas identitárias e fluxos culturais}

As Comunidades Eclesiais de Base16 (CEBs) tiveram nos dois contextos etnográficos um papel de valorização das histórias e memórias transmitidas 
oralmente, assim como provocaram um processo organizativo local visando a análise crítica das situações vividas ao mesmo tempo em que estimulavam a organização social e autonomia das comunidades que visavam consolidar.

A abertura democrática, a constituinte e o processo pós-constituição de 1988 foram assim marcantes nos dois contextos etnográficos, provocando a reconstrução identitária e o sentimento de pertença a um ou mais grupos, concomitante com a atualização dos fluxos culturais e o progressivo controle e disputa sobre os espaços de transmissão desses fluxos.

\section{O Auati-Paraná e a experiência das Comunidades Eclesiais de Base nos Movimentos Ambientalista e Indígenas}

A Igreja Católica no Brasil exercia, até os anos 1950, uma prática religiosa tradicional, "pouco presente na questão social, marcada pelo entendimento com as classes dominantes e, no campo, pela boa convivência com a oligarquia rural" (Lesbaupin, 2013: 17), corroborando com o esquema apresentado nas situações anteriores. No entanto, a atuação missionária foi sofrendo modificações nas décadas posteriores, motivada pela efervescência dos movimentos sociais no campo. Faulhaber (1998) afirma que a reestruturação das linhas de atuação da Pastoral da Amazônia na Conferência Nacional dos Bispos do Brasil (CNBB), definidas em 1972, propôs um conjunto de novas diretrizes baseadas na horizontalização da estrutura eclesiástica, que incluiu a atuação de agentes leigos na sustentação da mobilização para a criação das CEBs.

Este processo também incentivou as alianças entre grupos étnicos diversificados (entre indígenas e ribeirinhos), contribuindo para diminuir a força da consagração religiosa dos vínculos de compadrio, que reafirmavam a relação patrão-cliente. Em âmbito nacional, conforme Peixoto (1991), a ação progressista da Igreja Católica foi uma maneira de reagir à conjuntura política autoritária do Regime Militar. Apesar de alguns segmentos da Igreja manifestarem aceitação deste regime, outros segmentos dissidentes foram excluídos do bloco de poder instituído durante a Ditadura, que se concentrou na grande burguesia nacional e nas empresas multinacionais. Esta exclusão foi um fator decisivo para motivar o "reposicionamento do clero excluído no sentido de aliançar-se com o povo, em busca de uma base de poder" (Peixoto, 1991: 151).

De acordo com Peres (2003), o associativismo proporcionado pela Constituição Federal de 1988, cujo eixo é a noção de reconhecimento universal de uma cidadania diferenciada, substituiu o cristianismo pós Concílio Vaticano II de 1962, cujo princípio central era a opção preferencial pelos pobres. Deste modo, a Igreja se aliou a novos atores sociais, como ONGs, em substituição às Missões e adotou um novo mediador não indígena: o antropólogo-assessor. Além deste profissional, destacaram-se peritos como advogados, médicos, agrônomos, jornalistas, educadores, entre outros. Deste modo, um novo tipo de 
ação ganha importância: "colaboração científica ou técnica no lugar da pregação religiosa, mas ambas politicamente engajadas” (Peres, 2003: 158).

A tentativa de mudança de uma espécie de "consciência local", a partir da transformação da relação da população com o meio ambiente, em detrimento de um suposto comportamento individualista coincide com a proposta da Igreja Católica no Solimões, com a formação das CEBs, e a capacitação de agentes pastorais e monitores/animadores ou educadores. Aquela Igreja que outrora no Alto e Baixo Rio Negro e no Solimões tinha como missão a catequese e civilização dos índios, modifica sua forma de atuação, entre as décadas de 1970 e 8o, e institui a formação de líderes que transformariam a condição social precária da população. No caso do Alto/Baixo Rio Negro, enfatizando o desenvolvimento comunitário, conforme Peres (2013), e formando professores, líderes locais e agentes pastorais; e no caso do Solimões, introduzindo uma educação sindical e ambiental, conforme Silva (2016), coadunando com a característica local dos conflitos por uso e posse dos recursos naturais.

As viagens dos missionários se constituem como momentos de visita e discussão sobre a realidade vivida por esse "povo sofrido", categoria constantemente acionada pelos atores sociais da Igreja, e os meios para enfrentá-la. "Daí nasce uma teologia, uma espiritualidade profundamente encarnada na vida sofrida dos habitantes da floresta” (Derickx , 2007: 128). Este é o ponto de partida para a "teologia pé-de-chinelo", proposta no trabalho do padre João Derickx e da Prelazia de Tefé, o qual tem como base a valorização do pensamento e da forma de vida das pessoas na Amazônia, pois "eles pensam como vivem e vivem como pensam. O pé está quase sempre acompanhado do chinelo. Adoram e veneram seus santos. Constroem seus mundos, criam sua teologia, resistem...Eco/Teologia, Teologia Pé-de-Chinelo e outros são nomes que estamos dando..." (p. 128-9). Portanto, a "teologia pé-de-chinelo", embasase nas "opções básicas da caminhada": opção pelos pobres, respeito à cultura, promoção da vida, e tem como lema "um povo que anda com seus próprios pés" (p. 139).

A partir da estratégia pedagógica a disseminação de cursos de formação religiosa e política, o Movimento de Educação de Base tentava moldar um novo tipo de morador local: o comunitário preocupado com a situação social e política da região e mobilizado a modificá-la. A pedagogia cristã tinha como principal objetivo formar cristãos e cidadãos aptos para reivindicar seus direitos num contexto marcado por disputas políticas e desigualdades sociais, além disso, priorizava também o fortalecimento da identidade indígena que despontava naquele contexto.

As relações de patronagem, a ideia da pacificação/domesticação do meio ambiente e o controle do comportamento das pessoas envolvidas nesses projetos corroboram a noção de uma "tutela ambientalista", que Silva (2016) observou em campo, na qual os seres humanos devem viver em harmonia e sempre sob a guarda de um mediador externo, na figura do especialista ambiental, do pesquisador e do gestor para legitimar as intervenções políticas e administrativas. Esse processo foi possível a partir do desenvolvimento de um 
"ambientalismo-cristão", característico da região, que promoveu novos processos de territorialização, bem como da ação política de diversos empresários e comerciantes.

Simultaneamente, aqueles coletivos considerados invisíveis por segmentos sociais, como o "Estado", instituições patronais ou mesmo por coletivos indígenas reconhecidos, ingressaram em iniciativas dos Movimentos Indígenas e passaram a reivindicar seus direitos à educação, saúde e território. Ademais, o problema da identidade indígena "verdadeira" ou "legítima" ainda é um tema muito recorrente na área em questão, e ela pode ser também definida a partir da categoria "cadastro", por exemplo, na qual a pessoa é "cadastrada" como indígena ou "cadastrada" na Resex/RDS. Neste sentido, os atores sociais se apropriam das categorias burocráticas estatais no processo de construção social das fronteiras étnicas. Mesmo essas categorias sendo impostas pelo Estado, elas podem ser ressignificadas por eles para legitimar, reforçar ou mesmo invalidar afirmações identitárias em situação de conflito.

O "cadastro" pode ser entendido aqui como um mecanismo de disputa, onde o ato de categorizar o grupo ocorre fora e através da fronteira étnica, como Jenkins (2008) observou, partindo de Barth. Para Jenkins, a categorização social está intimamente vinculada às relações de poder, à capacidade de um dos grupos de impor com sucesso suas categorias de atribuição sobre o outro conjunto de pessoas e aos recursos pelos quais a coletividade categorizada pode basear-se para resistir à imposição exterior de comportamentos.

Assim como a negação ou a impossibilidade da afirmação da identidade étnica pode ser entendida como um mecanismo violento, a imposição externa da etnicidade a um determinado grupo que não deseja se reconhecer ou ser reconhecido também pode ser entendido como um ato violento. A opção ou não pela identidade étnica, num contexto caracterizado por conflitos parece se constituir como um ato consciente e político.

\section{Refazendo a história}

O processo das CEBs iniciado em 1987 em Conceição das Crioulas pode ser visto como um disparador para as pessoas que começam a se organizar numa "comunidade eclesial", através do tema e lema da Campanha da Fraternidade de 1988. Processo que ocorre num contexto de crescente organização das comunidades negras rurais no Pará, Maranhão e Bahia, que discutiam o direito às "terras de preto" (Almeida, 2008), assim como da recém aprovação do artigo 68 do Ato de Disposições Constitucionais Transitórias que cria uma categoria jurídica de "comunidades remanescentes de quilombo", reforçando uma ideia de que existiam comunidades que descendiam dos antigos quilombos históricos, aqueles presentes na legislação do Brasil Império que se mantém com parcas alterações até à abolição da escravidão como crime cometido em grupo.

O Serviço de Formação Pastoral da Igreja Católica inicia seu trabalho pela "construção de lideranças" (Antunes, 2016: 165) via processo de formação 
sociopolítica, envolvendo várias viagens para o entorno do município de Salgueiro, criando uma "gramática comunitária" e provocando torções em Conceição das Crioulas ao provocar um pensar-se enquanto parte de um grupo com uma história comum e com uma identidade negra e afrodescendente. A metodologia das CEBs, que propunha que as comunidades eclesiais analisassem seus problemas e traçassem soluções para os mesmos, buscando autonomizarse e conhecer os direitos que o "Estado" deveria prover, provoca fissuras nas alianças estabelecidas com os "patrões", que passam a ser denominados de "fazendeiros".

Com uma proposta de crescente angariação de membros para a comunidade, que se começa a construir sob a identidade de comunidade quilombola após 1994, os fluxos culturais disponíveis na oralidade começam a ser reorganizados dando conteúdo a essa categoria jurídica de "comunidade remanescente de quilombo" e transformando a mesma numa categoria identitária e de mobilização étnica por direitos que haviam sido recentemente legislados e que podiam ser acessados.

A escola de ensino fundamental e a Igreja são os espaços "públicos" ocupados para a construção da comunidade. Contudo, esses espaços eram submetidos ao controle dos fazendeiros e do padre a eles vinculado, pelo que rapidamente os encontros nesses espaços foram proibidos - as instituições econômicas, políticas e religiosas se entrelaçavam e mesclavam nessa repressão. A solução foi construir um espaço autônomo do "poder público" e gerido pela comunidade que se construía nesses encontros. Essa solução só foi possível porque parte das terras ficaram na posse de uma família descendente das seis crioulas que doou o terreno para a organização comunitária.

Era início da década de 1990 e a estratégia de mobilização comunitária se depara com a necessidade de mudar a relação com o "município", entendendo município como institucionalidade provedora de direitos e negadora de direitos, seja por ação, seja por omissão. Nesse sentido, em 1992 as lideranças construídas nos processos de formação política das CEBs e nos encontros locais, regionais e nacionais, assumem um papel na política partidária local e partem para a disputa por cargos políticos, apoiando uma candidata a prefeita e se candidatando a vereadores. A aliança com a prefeita que se elege em 1992 foi um passo importante para a mobilização local, pois através dessa aliança foi construída, em 1995, a escola de ensino fundamental passando a oferecer as séries entre a quinta e a oitava, além do que tanto essa escola como a outra (de $1^{\mathrm{a}}$ a $4^{\mathrm{a}}$ série) passaram a ter como diretoras lideranças comunitárias que colocaram em marcha uma educação escolar diferenciada17, antes mesmo de essa denominação passar a ser reivindicação do movimento quilombola.

Um processo de comunização étnica e política, num sentido weberiano, inicia-se nesse momento de abertura democrática, mas a categoria identitária quilombola, essa demora um pouco mais a ser incorporada nesse processo de "luta por direitos historicamente negados" como colocado por várias lideranças

${ }_{17}$ Para conhecer mais a respeito da discussão sobre educação escolar diferenciada em Conceição das Crioulas ver Silva (2012). 
de Conceição das Crioulas. A negritude era a dimensão étnica dessa mobilização e é a partir das relações com o Movimento Negro Unificado (MNU) e com o Centro de Cultura Luiz Freire (CCLF), que a comunidade em processo de construção, conduzido por algumas lideranças de diferentes famílias e localidades dentro do II Distrito de Salgueiro e articuladas no Sindicato de Trabalhadores Rurais (STR) do município, presidido por uma liderança de Conceição das Crioulas, se conecta com o movimento quilombola ainda em processo de gestação, no ano de 1994 e da sua fundação em 1995.

Dos terreiros das casas dos "mais velhos" para a sala de aula e espaços do "associativismo" (PERES, 2003), a transmissão da história e do jeito de ser e de fazer quilombola de Conceição das Crioulas continua privilegiando a oralidade e a experimentação, tendo a educação escolar diferenciada um papel chave nessa atualização de fluxos culturais. A escola, com sua gestão também diferenciada, juntamente com os espaços associativos vinculados ao STR, que se constituem em 2000 como a base da Associação Quilombola de Conceição das Crioulas (AQCC), refazem os laços do grupo, juntando troncos familiares de várias localidades que compõem o II Distrito, num processo de reconstrução do sentimento de pertença e de valorização da história de origem e destino comuns, construindo uma fronteira que inicia um processo de depuração dos intrusos em relação aos membros do grupo, desfazendo alianças com os fazendeiros, refazendo alianças entre os crioulos e crioulas de Conceição. Um processo que não abrange a totalidade da população nem no final da década de 1980, nem no início da década de 2000, mas que permite que entre 1994 e 1998 um laudo antropológico reconheça Conceição das Crioulas como "comunidade remanescente de quilombo" e que em 2000 o título do território quilombola seja atribuído à recém-fundada AQCC.

\section{Gestão territorial, alianças e conflitos}

Conflitos relacionados com a gestão territorial perpassam os dois contextos etnográficos e retroalimentam uma divisão étnica entre parentes de sangue, dividindo também as instituições que compõem o "Estado" na mediação (ou fomento) desses conflitos.

\section{"Onde tem conflito não tem manejo"}

Em Auati-Paraná os conflitos se articulam com a disputa do uso dos lagos e rebatem no controle exercido pelos órgãos gestores que desconsideram a história prévia de apropriação dos lagos pelas comunidades. A divisão imposta por uma política de zoneamento econômico-ecológico gera muitas tensões e desavenças, pois não dialoga com as estratégias de divisão do território e partilha dos lagos previamente realizada pelas comunidades. 
De acordo com um técnico do Instituto de Desenvolvimento Sustentável de Fonte Boa as regras são determinadas pelos indígenas e comunitários, mas a palavra final segue o curso da lei: "tem que seguir o que tá dentro da lei, ele não pode dizer que vai capturar o pirarucu o ano todo porque ele já tá ferindo a lei”. No cotidiano dos indígenas e dos comunitários esses passos nem sempre são seguidos e a burocratização das relações sociais que permeiam a prática do manejo é resultado da tentativa de "pacificação" dos coletivos e das pessoas enquanto indivíduos para que tenham condições de se relacionar entre si harmonicamente.

A administração das Unidades de Conservação pauta-se na "gestão de conflitos”, engendrada a partir do empenho na efetiva burocratização das unidades. Contudo, para os gestores, o grande problema enfrentado é que a partir desta burocratização surgiram novos conflitos nas comunidades. Esta outra maneira de partilhar o território implica num controle mais efetivo sobre as pessoas, que reagem. $\mathrm{O}$ argumento principal dos gestores na contenção de conflitos é: "onde há conflito, não tem manejo", uma das regras para o estabelecimento do processo civilizador: o uso racional dos recursos naturais.

O auge dos conflitos pode ser considerado o "Caso do Buiuçu", como ficou conhecido entre os gestores das Unidades de Conservação. Este caso representou um processo de engajamento em conjunto de diversos segmentos estatal/ambientalista, indígena/comunitário - pela permanência daquelas pessoas nas comunidades. A partir do momento em que um grupo de empresários proibiu a entrada dos indígenas e comunitários nos lagos do "Complexo do Buiuçu”, configurou-se um cenário propício para a resistência ao sistema de dominação concretizado na patronagem. Com o auxílio de juristas, os empresários construíram uma peça jurídica baseada na acusação de interesse financeiro por parte dos indígenas, peça que contrariava e contestava a identidade indígena dessas pessoas.

Os conflitos no Auati-Paraná ocorrem em variadas instâncias: entre os membros da família Arantes que residem nas comunidades de Santa União (indígenas Cocama) e de Itaboca (não indígenas); entre instituições estatais e comunidades; e entre as instituições responsáveis pelo controle do manejo da pesca18. De fato, a institucionalização do manejo do pirarucu pelo "Estado" reacendeu conflitos prévios, o que causou o rompimento entre os membros da família Arantes. As acusações entre os familiares não se restringiam apenas ao âmbito local-comunitário, mas os representantes de instituições estatais também entravam neste jogo. Enquanto alguns representantes do "Estado" afirmam se tratar de um conflito familiar ou "aquilo ali era briga de família", outros consideram a comunidade Santa União como precursora dos conflitos, chegando a revelar, de forma jocosa, que a chamavam de "Santa Confusão". A regra geral imposta pelas instituições gestoras-estatais se revela, dentre outras

${ }^{18}$ Instituto Chico Mendes de Conservação da Biodiversidade (ICMBio), Instituto Brasileiro de Meio Ambiente e dos Recursos Naturais Renováveis (IBAMA), Instituto de Desenvolvimento Sustentável de Fonte Boa (IDSFB), Instituto de Desenvolvimento Sustentável Mamirauá (IDSM) e o extinto Centro Estadual de Unidades de Conservação (CEUC). 
formas, a partir da reprodução do seguinte enunciado: "onde tem conflito não tem manejo".

Portanto, os conflitos estão relacionados com a produção de uma reputação local e externa: enquanto os membros de Santa União acreditavam estar trabalhando para uma espécie de "emancipação" frente às dificuldades estabelecidas pelo contexto histórico e social, mesmo que essa resistência significasse reagir ou lutar com afinco, ao olhar arbitrário e externo era produzida uma reputação negativa, levada a sério por muitos que não conheciam as histórias locais e os seus desdobramentos.

A partir da construção do "Caso do Buiuçu”, a relação de patronagem tal como conhecemos ultrapassou os limites de uma relação informal e se concretizou num acordo em juízo, no qual os indígenas (de Santa União) e comunitários (de Itaboca) passaram por diversos momentos de coação para se adequarem ao sistema instituído há muitos anos e atualizado via peça jurídica. No entanto, a partir da reação a este processo foi possível a produção de uma "causa", nos termos de Boltanski (1993), considerando que o evento só se transforma em causa, a partir do momento em que se inscreve no âmbito social, coletivo e político.

A luta pelos direitos e permanência em seu local de origem está basicamente fundada na gestão de conflitos. Esses conflitos suscitados nas comunidades e nos espaços de gestão são muito mais do que um fenômeno de sociação, conforme Simmel (1955), atuando na resolução de divergências e produção de algum tipo de unidade social. No caso estudado, eles podem ser considerados como efeitos sociais da resistência a essa precarização e burocratização da vida cotidiana, resultado da introdução de marcas e nomeações que se instituíram ao longo da história das famílias envolvidas.

Mesmo com a mobilização do IBAMA e de outras instituições em prol dos direitos dos comunitários e indígenas, havia uma tensão entre os membros da família Arantes, que culminou na quebra do acordo de pesca em 2010 e futuramente geraria embates físicos. Essa tensão se desenvolvia em paralelo ao processo de definição e de posição coletiva frente às instituições ambientalistas e governamentais. O Movimento Indígena expandia sua atuação, com reuniões ao longo do Solimões no trabalho de divulgação dos direitos indígenas e identificação de grupos que desejavam regulamentar suas terras de origem ou necessitavam de auxílio nas questões de conflito de terra.

O ingresso formal de Santa União na participação efetiva nos Movimentos Indígenas significou grande apoio para a comunidade no sentido de orientação para a organização da associação e articulação com outras instituições a fim de mediar o conflito com os empresários e, mais tarde, com os parentes. Durante uma conversa coletiva na comunidade Santa União, os indígenas explicitaram os motivos da "briga de família", no qual os indígenas se ressentiam com seus parentes de Itaboca por negarem a identidade indígena, bem como terem se envolvido em negociações com os patrões e empresários locais. Deste modo, o 
conflito se deslocou gradativamente do âmbito institucional e se manifestou nas relações familiares, revelando outro sentido de político: inimigo19.

Conforme Joel Ferreira Arantes, que na ocasião era presidente da associação da comunidade de Santa União, “o nosso parente tá político com nós, por esse lado aí. Eles querem se mostrar que não são índio. Como nós se reconhecemo como índio, nós vamo até o fim”. Esse reconhecimento tanto interno quanto externo representa um movimento que ocorre desde o final da década de 1990 nas calhas do Rio Solimões, que atualmente é chamado de "passar pra índio"20. Tal atitude pode ser encarada tanto num sentido pejorativo, quanto relacionado à atuação da política indígena local. Para os membros de Santa União, o processo de passar pra índio envolve duas vias interligadas:

1. Significa estabelecer a relação de posse de um território indígena, ou seja, transformar um território (geralmente disputado, em litígio) em área indígena, em patrimônio indígena como uma espécie de reação à precarização à qual o Estado tentou submetê-los; e

2. Significa reivindicar os direitos perante o Estado, ter o reconhecimento da legitimidade indígena frente aos órgãos competentes, como FUNAI, FUNASA, órgãos ambientalistas, entre outros, representando também a ressignificação do fazer político num âmbito privado e público.

A mobilização e demanda pela demarcação da Terra Indígena Santa União trouxe à tona e reforçou os mais diversos estigmas na região. Pleitear uma Terra Indígena implicou automaticamente em assumir a identidade indígena, algo que não agradou aos comunitários. Deste modo, o inimigo localiza-se em dois planos: o "Outro" distante e institucional: o governador e os empresários e seus funcionários, que neste caso decorre da relação de opressão que vem se arrastando há muitos anos; e o "Outro" próximo: os parentes que não se identificaram com a causa indígena, algo que os Cocama acreditam ser um direito.

Segundo os Cocama, o erro dos comunitários foi ter "traído" a família. Para eles, a traição foi: a opção inicial dos comunitários em continuar trabalhando para o empresário e ter permanecido no projeto da Resex; a negação da identidade indígena por parte dos parentes; e a hostilidade e estigmatização dos Cocama praticadas por parte dos parentes comunitários. Nestes três elementos da traição encontram-se a chave para a luta pelo território e a busca pela dignidade. Esta questão é sempre reeditada a cada narrativa sobre os conflitos, e aponta para a força das alianças (sejam de vizinhança ou de parentesco) no desenvolvimento das suas reivindicações.

${ }_{19}$ Para os indígenas e a população local, político ou estar político é sinônimo de inimigo, daquele que faz intriga e conflito, de estar indisposto com alguém, ou seja, a caracterização do Outro. Político é o contrário do conciliador, é o provocador de conflito. "Ser político não é uma boa coisa", demonstrando claramente uma conotação maligna da política. O político é alguém que não sabe se relacionar ou se entender com as pessoas. O político é aquele que não consegue se entender com as pessoas. E, para os indígenas, é aquele que tem e dissemina o preconceito por acreditar que os indígenas representam uma ameaça a sua hegemonia.

${ }_{20}^{2}$ Passar pra índio é um termo muito utilizado no Médio Solimões para indicar que um agrupamento ou comunidade "decidiu" reivindicar a identidade indígena. Souza (2011) em sua dissertação define o termo da seguinte maneira: "O passar para indígena em uma comunidade é um processo que envolve a escolha de um etnônimo, reconhecimento entre seus pares (outros parentes indígenas e lideranças do movimento indígena) e matrícula dos moradores na FUNAI" (p.16). 


\section{A volta fatiada da terra}

A titulação do território quilombola de Conceição das Crioulas, juntamente com a ausência de instrumentos administrativo-legais de indenização dos títulos de propriedade e benfeitorias inseridos no perímetro do território quilombola de Conceição das Crioulas, acirrou os conflitos entre aqueles que se construíam como quilombolas desde 1994 e aqueles que eram construídos como intrusos. Conflitos esses permeados por ameaças de morte e por cobrança de dívidas morais de respeito aos fazendeiros que se colocavam como os responsáveis pela sobrevivência daquela população.

Esses conflitos vão se produzindo em meio ao processo de comunização etnicopolítico em curso em Conceição das Crioulas e como demonstrado por Antunes (2016) foram produzindo o reverso desse processo - a descomunização. Essa descomunização se reflete na divisão interna à comunidade de Conceição das Crioulas, num sentido mais amplo de comunidade como reflexo de uma divisão político-administrativa alinhada com o total de habitantes do II Distrito de Salgueiro, em duas comunidades étnicas quilombola e indígena -, com as decorrentes acusações de legitimidade e ilegitimidade dessas autoidentificações e processos conflitantes de comunização.

São vários os fatores interconectados que alimentam esses conflitos, dos quais se destacam: a atuação dos órgãos da burocracia estatal que dividem sua atuação entre indígenas e quilombolas sem que diálogos sejam forjados para pensá-las conjuntamente ou de forma articulada; o tempo estendido da política de regularização fundiária quilombola e as mudanças sucessivas no quadro normativo que regulamenta a atuação das instituições estatais nesse processo, o que gera múltiplas incertezas em vários atores afetados positiva e negativamente por esse processo; a inserção nas redes de sociabilidade local dos fazendeiros e sua articulação com o município - seja com vereadores(as) ou com o(a) próprio(a) prefeito(a); o papel da igreja católica; e o papel do medo da perda dos "territórios familiares".

Para compreender a possibilidade da autoidentificação etnicamente diferenciada de membros das mesmas famílias, descendentes de grandes troncos comuns, é preciso lembrar a particularidade do processo de colonização do sertão pernambucano e da interação e ajuda tecida entre indígenas e africanos, ou seus descendentes, que escapavam da escravidão21. Conceição das Crioulas situa-se num vale rodeado de serras e permeado de serrotes, sendo essas serras parte dos trajetos de mobilidade das populações indígenas nos séculos que sucederam a interiorização da colonização, com o avanço do gado pelos sertões. Quando as seis negras chegam nesse território, o mesmo fazia fronteira com o território ocupado pelos indígenas Atikum-Umã, com os quais

${ }^{21}$ Consultar, entre outros, Grünewald (2004 e 2011), Mura (2012) e Oliveira (2004). 
dividiam a Serra das Crioulas e com os quais forjaram laços de parentesco e religiosos.

A divisão étnica começa a se visibilizar após a titulação do território quilombola de Conceição das Crioulas em 2000 e quando a ansiedade em relação aos próximos passos - em particular as indenizações de terras - começa a ser expressa pelos fazendeiros na mídia local e nas ameaças de morte, que se tornam mais graves no ano de 2004.

A etnificação (Peres, 2013) enquanto indígena do grupo que se torna oposição aos que se organizavam na AQCC, e que se preparavam para a gestão comunitária do território titulado enquanto quilombo, retoma a mesma linguagem do parentesco - acionando ancestrais indígenas, a maioria da Serra de Umã e da Serra do Arapuá - e estabelece no genocídio indígena ocorrido na Serra do Urubu e provocado pelo avanço do gado pelo sertão um mito de origem, mesmo não colocando sua ancestralidade nos sobreviventes desse genocídio e sim em grupos indígenas com etnônimos reconhecidos pela burocracia estatal, alguns bem distantes do território hoje denominado como quilombola.

Esse processo adentra a burocracia estatal como uma denúncia de "sobreposição" territorial e aos poucos vai se solidificando numa demanda de ampliação da terra indígena Atikum-Umã delimitada em 1993. Aquilo que era visto como um desentendimento, fruto de alianças políticas e projetos de territorialização conflitantes, mas passível de solução entre os grupos, se transforma num processo jurídico que demanda a intervenção da FUNAI órgão responsável pela política para indígenas - e do INCRA - órgão responsável pela regularização fundiária do território quilombola - juntamente com a FCP - órgão responsável pela emissão da certificação de reconhecimento da comunidade como quilombola - e com a SEPPIR - órgão que seria responsável pela coordenação de todas as políticas atravessadas pela questão racial.

A leitura realizada por Antunes (2016) das atas das três audiências públicas realizadas, envolvendo os representantes dos dois grupos étnicos e os órgãos responsáveis por políticas públicas direcionadas aos mesmos, mostra que estes últimos buscam simultaneamente "pacificar" o conflito e dar continuidade ao seu passo a passo burocrático na lide com essas populações, mesmo passo a passo que retroalimenta os conflitos. Colocando nas populações a responsabilidade pelo conflito e se eximindo de qualquer responsabilidade pelo mesmo. A intervenção do MPF nessas audiências é de mediador entre as populações e entre os órgãos, buscando forjar acordos e compreender porque os mesmos foram descumpridos entre uma audiência e outra.

Em paralelo, a AQCC vem estimulando desde 2004, com interrupções alinhadas com as paradas forçadas no processo de regularização fundiária liderado pelo INCRA, um processo de construção comunitária de normas para a gestão territorial, independente da intervenção estatal, mas alinhada com as leis, as normas e os acordos estabelecidos nas audiências públicas. Processo que busca recomunizar os dois grupos enquanto uma comunidade - a comunidade 
de Conceição das Crioulas -, independente da autoidentificação étnica acionada. Essa busca de recomunização está latente nas normas forjadas que permitem a todos os que têm o que Antunes denominou de "identidade em potencial" (2016), ou seja, vínculos de parentesco e com o território, mesmo que não a acionem, ou seja, mesmo que não contribuam para a construção de um "nós-quilombola" e com a luta pela regularização fundiária do território, possam permanecer em território titulado como quilombola, mesmo após a desintrusão completa do mesmo. Nesse sentido, as lideranças que compõem o Grupo de Trabalho de Gestão do Território, lócus onde essas normas são construídas e negociadas, demonstram que todos aqueles que não são "fazendeiros" e que têm vínculos de parentesco são bem vindos e não precisam temer a perda de seus "territórios familiares", que a gestão do território liderada pela AQCC vai respeitar esses espaços e se debruçar apenas sobre as fazendas desintrusadas para pensar o governo da relação entre população e território quilombola. Nesse sentido, as normas comunitárias parecem mais capazes de dialogar com a historicidade das relações entre população e território do que o traçado burocrático que criou fronteiras retas e que cortou comunidades ao meio, deixando parte dentro da terra indígena Atikum-Umã e metade dentro do território quilombola de Conceição das Crioulas. Fronteira inicialmente rotulada como imaginária, mas que se materializou em meio aos conflitos tornando-se alvo de demanda de redelimitação.

\section{Considerações finais}

Conscientes que colocamos em diálogo dois contextos etnográficos distantes e que os recortes operados nos mesmos visavam esse diálogo, sendo que em momento algum pretendemos comparar dois grupos étnicos, e sim pensar formas de atualização de fluxos culturais que permitem que "parentes de sangue" se autodefinam como etnicamente diferentes, tecemos aqui algumas considerações finais.

Primeiro destacamos o papel da história na constituição da possibilidade da existência de "lados" em conflito dentro das mesmas famílias e na forma como as fronteiras étnicas e territoriais se entrelaçam com essa história. Salientamos como as relações com "patrões" e depois "empresários" ou "fazendeiros" têm o potencial de esgarçar o tecido que interliga os membros das mesmas famílias e de criar outros circuitos de acesso a recursos naturais, econômicos, sociais e políticos que passam por relações mais individualizadas com esses patrões que vão se metamorforseando em "empresários" ou "fazendeiros", assim como se limpando das imagens de exploração e violência exercidas por eles sobre as comunidades e territórios em análise.

Destacamos também o processo constante de deslegitimização de sua afirmação étnica enquanto indígenas (Auati-Paraná) e enquanto quilombolas (Conceição das Crioulas) que esses grupos são alvo, processo que é exercido por múltiplos atores - os membros dos grupos com os quais se conflitam, os órgãos 
da burocracia estatal, a Igreja - e que retroalimenta o conflito e sua duração no tempo, impedindo a solução "pacificadora" que os órgãos estatais tanto buscam, como se eles mesmo não fossem parte do "problema" que buscam "solucionar".

A forma como cada lado em conflito, nos dois contextos etnográficos, aciona a história e memória coletiva para justificar seu posicionamento étnico e político trazem matizes interessantes para pensar a questão da etnicidade. Tanto os Cocama, quanto os quilombolas de Conceição das Crioulas mergulham na história oral em busca da origem comum, a dos primeiros remonta ao Peru e ao final do século XIX e início do século XX, e a dos últimos ao sertão da antiga comarca de Pernambuco e tem como data chave 1802. Nessa antiguidade firmam sua legitimidade étnica e se defendem das acusações de falsidade, ao mesmo tempo em que utilizam a ideia de serem todos a mesma família para deslegitimarem aqueles que não querem assumir a luta, a resistência, aqueles que "traem" o grupo e negam sua história, se aliando a "outros" que os exploraram no passado, por vezes não tão distante.

Como apontamos ao longo da apresentação, a filiação de cada lado em conflito nos dois contextos a políticas públicas e seus órgãos gestores que pensam esses grupos como possuidores de fronteiras estáveis e estanques indígenas e FUNAI, quilombolas e INCRA/FCP/SEPPIR, comunitários ou ribeirinhos e IBAMA -, conjuntamente com a reorganização territorial operada de forma burocrática e por vezes cheia de linhas retas traçadas nos mapas da administração pública e com normas de atuação desenhadas com parco diálogo com as populações afetadas permeiam o processo de gestão territorial de conflitos que se arrastam no tempo e que exigem do mesmo "Estado" o dirimir dos mesmos - seja através de Planos de Manejo ou de audiências públicas com o MPF.

Os dois contextos apontam ainda que ao mesmo tempo em que os laços de parentesco e os vínculos com o território de tempos imemoriais são acionados como legitimadores da autoidentificação étnica, eles são relativizados ao permitir as exceções entre aqueles que são da luta e que passam a ser incorporados aos grupos. No Auati-Paraná essa aceitação pressupõe um engajamento nos Movimentos Indígenas, no caso de Santa União, ou a aceitação das regras do Plano de Manejo Participativo, no caso dos extrativistas da Resex, em ambas, com um objetivo em comum: a mudança na condição social da população local. Em Conceição das Crioulas é preciso que aqueles que têm a "identidade quilombola em potencial" (ANTUNES, 2016) a acionem e adentrem o espaço da luta e resistência, assim como aqueles que não possuem essa "identidade em potencial" tenham demonstrado ser de luta. Ademais as pessoas que vierem a constituir laços matrimoniais com algum(a) quilombola podem acessar os frutos da luta - as terras desintrusadas - desde que aceitem as regras de "gestão territorial comunitária" (idem) presente no mais recente estatuto da associação quilombola - a AQCC.

A questão da delimitação das fronteiras (sociais e burocráticas) e configuração territorial das comunidades aqui apresentadas, como foi possível observar, são temas que perpassam os contextos apresentados. A maneira como 
se constrói essa noção de comunidade e a gestão coletiva dos territórios, analiticamente, está intimamente ligada com as relações de poder fundantes das estratégias do rearranjo territorial forjadas ao longo da história dessas comunidades. 


\section{Bibliografia}

ALMEIDA, Alfredo Wagner Berno de. Terra de quilombo, terras indígenas, "babaçuais livre", "castanhais do povo", faixinais e fundo de pasto: terras tradicionalmente ocupadas. $2^{\text {a }}$ Ed, Manaus: PGSCA-UFAM, 2008.

ANTUNES, Marta de Oliveira. A terra que volta: gerindo territórios, memórias, conflitos e normas em Conceição das Crioulas. Tese de doutorado em Antropologia Social. Rio de Janeiro: PPGS/MS/UFRJ, 2016.

AQCC. Nosso território: Conceição das Crioulas. CRIOULAS - A voz da resistência. Recife: AQCC. 2013.

BARTH, Fredrik. O guru, o iniciador e outras variações antropológicas. Organização de TomkeLask. Rio de Janeiro: Contra Capa Livraria, 2000.

.Temáticas permanentes e emergentes na análise da etnicidade" In:VERMEULEN, Hans e GOVERS, Cora. Antropologia da Etnicidade. Para além de "Ethnic groups and boundaries". Lisboa: Fim de Século, 2003, pp. 1944 .

BATES, Henry Walter. Um naturalista no Rio Amazonas. Belo Horizonte: Itatiaia; São Paulo: EDUSP, 1979.

BASTOS, A. C. Tavares. O vale do Amazonas: a livre navegação do Amazonas, estatística, produções, comércio, questões fiscais do vale do Amazonas. Brasiliana vol 106. 3. Ed. São Paulo: Cia Editora Nacional, Brasília: INL, 1975.

DIAS, Edinea Mascarenhas. A ilusão do Fausto: Manaus 1890-1920. 2.ed. Manaus: editora Valer, 2007.

FAULHABER, Priscila. O Lago dos Espelhos. Etnografia do Saber sobre a Fronteira em Tefé/Amazonas. Belém: Museu Goeldi, 1998.

GRÜNEWALD, Rodrigo de Azeredo. "Legitimidade étnica no encontro entre índios e negros". In CARVALHO, Maria do Rosário, REESINK, Edwin e CAVIGNAC, Julie (orgs.). Negros no mundo dos índios: imagens, reflexos, alteridades. Natal, RN: EDUFRN, 2011, pp.361-385.

Etnogênese e 'regime de índio' na Serra do Umã. In: OLIVEIRA, João Pacheco de (org.) A viagem de volta: etnicidade, política e reelaboração cultural no Nordeste indígena. $2^{\mathrm{a}}$ Ed. Rio de Janeiro: Contra-capa Livraria/LACED. 2004, pp. 139-174.

JENKINS, Richard. Rethinking Ethnicity. Arguments and explorations. 2.ed. London: Sage Publications, 2008.

LESBAUPIN, Ivo. A Igreja e a ditadura militar. In: ASSIS, João Marcus Figueiredo; RODRIGUES, Denise dos Santos (orgs.). Cidadania, movimentos 
sociais e religião: abordagens contemporâneas. Rio de Janeiro: EdUERJ, 2013.

MAUSS, Marcel. "Ensaio sobre a dádiva. Forma e razão da troca nas sociedades arcaicas”. Sociologia e antropologia. São Paulo: CosacNaify. 2003, pp. 47-181.

MURA, Claudia. 'Todo mistério tem dono!': ritual, política e tradição de conhecimento entre os Pankararu. Rio de Janeiro: UFRJ/ Museu Nacional PPGAS. 2012. xiii, $339 \mathrm{f}$.

OLIVEIRA, João Pacheco de. "Pacificação e tutela militar na gestão de populações e territórios”. Mana: estudos de antropologia social. Museu Nacional, Departamento de Antropologia, Programa de Pós-graduação em Antropologia Social. Rio de Janeiro, volume 20, número 1, abril de 2004, pp. 125-161.

"Uma Etnologia dos 'Índios Misturados'? Situação Colonial, Territorialização e Fluxos Culturais". In OLIVEIRA, João Pacheco de. A viagem de volta: etnicidade, política e reelaboração cultural no Nordeste indígena. $2^{\mathrm{a}}$ ed. Rio de Janeiro: Contra Capa Livraria / LACED. 2004, pp. 13-42.

. "Ação indigenista e utopia milenarista: as múltiplas faces de um processo de territorialização entre os Ticuna” In ALBERT, B. (Org.) Pacificando o branco: cosmologias do contato no Norte-Amazônico. São Paulo: UNESP, 2002, pp. 277-309.

Ensaios em Antropologia Histórica. Prefácio de Roberto Cardoso de Oliveira. Rio de Janeiro: Editora UFRJ. 1999. 272p.

O 'Nosso Governo': os Ticuna e o regime tutelar. Tese de Doutorado. Rio de Janeiro: UFRJ, 1986.

PEIXOTO, Rodrigo. Ação cultural e concepção política entre a igreja católica e os camponeses (um estudo na região de Marabá). In: LÉNA, Philippe; OLIVEIRA, Adélia E. de. Amazônia: a fronteira agrícola 20 anos depois. Belém: MPEG, 1991.

PERES, Sidnei Clemente. A Política da Identidade: Associativismo $e$ Movimento Indígena no Rio Negro. Manaus: Editora Valer. 2013, 420p.

Cultura, política e identidade na Amazônia: o associativismo indígena no Baixo Rio Negro. Tese (doutorado) - Campinas, SP: Universidade Estadual de Campinas, Instituto de Filosofia e Ciências Humanas, 2003. 447fs.

REIS, Arthur Cezar Ferreira. O seringal e o seringueiro. Rio de Janeiro: Ministério da Agricultura. Serviço de Informação Agrícola, 1953.

SHIRASHI Neto, Joaquim. Direito dos Povos e das Comunidades Tradicionais no Brasil: Declarações, Convenções Internacionais e Dispositivos Jurídicos definidores de uma Política, Manaus: UEA, 2007. 
SILVA, Katiane. Parente é serpente: ambientalismo, conflitos sociais e uso de recursos naturais no Auati-Paraná, Amazonas / Katiane Silva. - Rio de Janeiro: UFRJ, 2015.

Muito além do conflito. Política, patronagem, ambientalismo e resistência indígena no Auati-Paraná, Alto Solimões, Amazonas. In LACERDA, Paula. Mobilização social na Amazônia [recurso eletrônico]: a 'luta' por justiça e por educação / organização Paula Lacerda. - 1. ed. - Rio de Janeiro: E-Papers, 2014.

TASTEVIN, Constant. A região do Solimões ou Médio-Amazonas. In: FAULHABER, Priscila e MONSERRAT, Ruth. (orgs.). Tastevin e a etnografia indígena. Coletânea de traduções de textos produzidos em Tefé (AM). Séries Monografias. Rio de Janeiro: Museu do Índio, 2008.

TEIXEIRA, Carlos Corrêa. Servidão humana na selva: o aviamento e o barracão nos seringais da Amazônia. Manaus: editora Valer, EDUA, 2009.

WEBER, Max. "I. Conceptos sociológicos fundamentales"; "IV. Comunidades étnicas". Economía y sociedad. Espanha: Fondo de Cultura Económica. Segunda reimpressão. 2002. pp. 5-45; 315-327. 